\title{
Alcohol withdrawal management in patients undergoing head and neck reconstruction-a retrospective analysis
}

\author{
Yuan Liu ${ }^{1}$, Yanshu $\mathrm{Xu}^{2}$, Qingyang $\mathrm{Li}^{2}$, Ling Zhang ${ }^{1,3,4}$ \\ ${ }^{1}$ Department of Oral and Maxillofacial-Head and Neck Oncology, Shanghai Ninth People's Hospital, College of Stomatology, Shanghai Jiao Tong \\ University School of Medicine, Shanghai, China; ${ }^{2}$ Department of Anesthesiology, Fengcheng Hospital, Shanghai, China; ${ }^{3}$ National Clinical Research \\ Center for Oral Diseases, Shanghai, China; ${ }^{4}$ Shanghai Key Laboratory of Stomatology \& Shanghai Research Institute of Stomatology, Shanghai, \\ China \\ Contributions: (I) Conception and design: Q Li, L Zhang; (II) Administrative support: L Zhang; (III) Provision of study materials or patients: Y Liu; \\ (IV) Collection and assembly of data: Y Liu; (V) Data analysis and interpretation: Y Xu; (VI) Manuscript writing: All authors; (VII) Final approval of \\ manuscript: All authors. \\ Correspondence to: Qingyang Li. Department of Anesthesiology, Fengcheng Hospital, Chuannanfeng Road, No. 9983, Shanghai 200011, China. \\ Email: 18916111970@189.cn; Ling Zhang. Department of Oral and Maxillofacial-Head and Neck Oncology, Shanghai Ninth People's Hospital, \\ Zhizaoju Road, No. 639, Shanghai 200011, China. Email: topgun1128@163.com.
}

\begin{abstract}
Background: Alcohol abuse is common in the patients with head and neck cancer. Sudden postoperative alcohol cessation can cause alcohol withdrawal syndrome (AWS). So far, there are no studies evaluating the safety and efficacy of dexmedetomidine (DEX) and lorazepam on AWS treatment.

Methods: In this study, we assessed the safety and efficacy of DEX and lorazepam on AWS treatment. Patients meeting our study criteria were further screened for alcohol dependence using the CIWA-Ar questionnaire and treated with DEX or lorazepam.

Results: This study was conducted in a cohort of 59 patients with mean age of 65.8 years. In DEX group ( $n=33$ ), for the time to recover, after the AWS, most people relieved within 3 days $(26 / 33)$, some patients relieved till 5 days (2/33) and others needed more than 7 days (5/33). Mean time of recovering was $3.2 \pm 2.2$ days. Total 9 cases of complications and tracheotomy after surgical reconstruction occurred and its mean time of recovering was $5.1 \pm 2.8$ days. In lorazepam group $(n=26)$, for the time to recover, after the AWS, most people relieved within 3 days (21/26), some patients relieved till 5 days (2/26) and others needed more than 7 days (3/26). Mean time of recovering was $3.2 \pm 2.1$ days. The incidence of complications and tracheotomy was $15.4 \%$ (4/26) and its mean time of recovering was $4.0 \pm 3.5$ days.

Conclusions: Our retrospective study found there is no significant difference in recovering time of AWS, complications occurring and its recovering time, after randomly accepting DEX or lorazepam.
\end{abstract}

Keywords: Dexmedetomidine (DEX); lorazepam; alcohol withdrawal syndrome (AWS); head and neck cancer; reconstruction surgery

Received: 10 June 2021; Accepted: 21 October 2021; Published: 10 December 2021.

doi: $10.21037 /$ fomm-21-76

View this article at: https://dx.doi.org/10.21037/fomm-21-76

\section{Introduction}

China is a country with a large production and consumption of alcohol. It is estimated that the average alcohol consumption was $11,000 \mathrm{~mL}$ in Chinese male, which is much higher than the international annual adult per capita consumption $6,500 \mathrm{~mL}(1,2)$. It is well known that head and neck cancers are strongly linked to alcohol abuse and chronic alcohol consumption raises the risk of developing oral squamous cell carcinoma (3). Many patients with head and neck cancer become physiologically dependent on alcohol after a period of excessive use and 
abrupt postoperative alcohol cessation increases the risk of developing alcohol withdrawal syndrome (AWS). AWS can occur 12 hours after alcohol cessation and is typically characterized by a set of symptoms including confusion, tremors, seizures and delirium tremens (4). Delirium tremens is the most severe form of AWS (5). During postoperative delirium tremens, behavioral complications are often observed in patients with head and neck cancer including self-catheter removal, self-extubating and selfremoval of nasal feeding tubes, causing a poor prognosis (6). In addition, these behavioral complications may also lead to hematoma, flap crisis, flap necrosis of postoperative head and neck reconstruction and prolonged length of hospital stay (7). AWS is one of the complications of alcohol abuse patients undergoing radical mastectomy and reconstruction. Sedation plays a key role in the management of AWS (8). Common drugs used by clinicians are dexmedetomidine (DEX), propofol and benzodiazepines (most commonly midazolam and lorazepam) for sedation in an intensive care setting. Maintaining a light level of sedation in ICU patients is recommended, when possible, given that light sedation is associated with improved outcomes, including a shorter duration of ventilation and a shorter ICU stay (9).

The selective $\alpha-2$ adrenoceptor agonist DEX has sedative and analgesic properties. It can provides "conscious sedation" where patients appear to be asleep but readily roused, analgesia without respiratory depression (10). In clinical work, it is used for sedation during tracheal intubation and mechanical ventilation of surgical patients undergoing general anesthesia. DEX had analgesic effects and an opioid-sparing effect in patients in an intensive care setting. Besides, it can stabilize blood pressure (11). These characteristics provide a treatment plan for AWS in patients undergoing head and neck tumor resection and reconstruction surgery.

Benzodiazepines are considered as first-line pharmacological treatment of AWS. Benzodiazepines act as $\gamma$-aminobutyric acid (GABA) receptor mediators and relieve symptoms of AWS by increasing the effects of GABA representing reduction in seizures and delirium (12). AWS patients with abnormal liver function should be used with fast-metabolized short half-life benzodiazepines, such as oxazepam and lorazepam. Lorazepam is an orally available benzodiazepine used widely in the therapy of anxiety and insomnia (13). Lorazepam is currently recommended by the Society of Critical Care Medicine (SCCM) in its clinical practice guidelines for the sustained sedation of mechanically ventilated ICU patients (14).
The efficacy of DEX and lorazepam on AWS treatment has been reported in head and neck patients (15-17). These two drugs are the most commonly used to treat AWS in our clinical work. However, no study has been carried out to compare the efficacy and safety of DEX and lorazepam for AWS treatment in head and neck cancer patients. The objective of this study was to compare the efficacy and safety of head and neck cancer patients suffering AWS who received DEX or lorazepam therapy. We present the following article in accordance with the STROBE reporting checklist (available at https://fomm.amegroups.com/article/ view/10.21037/fomm-21-76/rc).

\section{Methods}

\section{Patient selection and study design}

This study was conducted at the Ninth People's Hospital, Shanghai Jiao Tong University School of Medicine, China. Patients were diagnosed with head and neck cancer by the Department of Oral-Maxillofacial Head and Neck Surgery at the Ninth People's Hospital Shanghai. The study was conducted in accordance with the Declaration of Helsinki (as revised in 2013) and individual consent for this retrospective analysis was waived.

This investigation was a retrospective study, which was carried out in head and neck cancer patients from January 2015 to December 2020, who accepted surgical reconstruction and were diagnosed as postoperative AWS. Patients with confirmed or suspected AWS were identified by the attending or admitting physician. According to DSM-5, AWS diagnosis is established when patients present at least two of the following symptoms: tremors, sweating, tachycardia, insomnia, nausea or vomiting, illusions, transient hallucinations (auditory, visual or tactile), psychomotor agitation, anxiety or seizures. The Clinical Institute Withdrawal Assessment-Alcohol revised (CIWA-Ar,) is a tool to assess AWS symptoms and allows the assessment of the effectiveness of the clinical therapy (18). A score $<8$ defines a mild AWS; a score between 8 and 15 defines a moderate AWS; a score $>15$ defines a severe AWS. CIWA-Ar scores are documented at least every 4 hours and after an intervention. So, the selection criteria include: (I) diagnosed as AWS by a specialist; (II) use DEX or lorazepam treatment. Exclusion criteria: (I) history of taking psychiatric drugs; (II) being diagnosed with mental illness or having related medical history, such as hepatic encephalopathy, delirium and 
Table 1 Demographic characteristic (N=59)

\begin{tabular}{|c|c|c|c|}
\hline $\begin{array}{l}\text { Demographic } \\
\text { characteristic }\end{array}$ & Dexmedetomidine & Lorazepam & $P$ value \\
\hline Age & & & - \\
\hline Mean (SD) & $66.8(7.0)$ & $64.6(6.2)$ & \\
\hline Median & 66.0 & 63.5 & \\
\hline Sex & & & - \\
\hline Male & 32 & 26 & \\
\hline Female & 1 & 0 & \\
\hline Tumor stage & & & - \\
\hline $\mathrm{T} 2$ & 7 & 4 & \\
\hline T3 & 15 & 17 & \\
\hline T4 & 11 & 5 & \\
\hline Locations & & & - \\
\hline Tongue & 21 & 12 & \\
\hline Buccal & 5 & 8 & \\
\hline Floor of month & 2 & 4 & \\
\hline Gingival & 3 & 1 & \\
\hline Lip & 1 & 0 & \\
\hline Mandible & 1 & 0 & \\
\hline Sinus & 0 & 1 & \\
\hline Time to recover & & & 0.87 \\
\hline Mean (SD) & $3.2(2.2)$ & $3.2(2.1)$ & \\
\hline Complications & & & 0.27 \\
\hline With & 9 & 4 & \\
\hline Without & 24 & 22 & \\
\hline \multicolumn{2}{|c|}{ Time to recover with complications } & & 0.55 \\
\hline Mean (SD) & $5.1(2.8)$ & $4.0(3.5)$ & \\
\hline
\end{tabular}

SD, standard deviation.

Wernicke Korsakoff syndrome. Reviewing the medical history, there were a total of 90 people with AWS symptoms. According to our exclusion criteria, 31 patients were excluded. Fifty-nine $(\mathrm{n}=59)$ patients were enrolled in the retrospective study and they accepted the treatment of DEX Group ( $n=33)$ or lorazepam Group $(n=26)$, respectively (Table 1). Stop pharmacological intervention when CIWA-Ar score is $<8$. The collected variables included time to recover (day), complications and time to recover with complications (day).

\section{DEX treatment}

DEX is a sedative drug to induce anesthesia. Patients in this group started to receive $0.4 \mu \mathrm{g} / \mathrm{kg}$ intravenous DEX for 1 hours, and the dose may be increased if symptoms of AWS continued to progress. The maximum daily dose of DEX was $1.2 \mu \mathrm{g} / \mathrm{kg}$. DEX was dissolved in $0.9 \%$ sodium chloride to obtain solutions of final concentrations ranging from 4 to $12 \mu \mathrm{g} / \mathrm{mL}$. Temporary discontinuation of intravenous DEX treatment was necessary for patients with bradycardia (heart rate $<50$ beats $/ \mathrm{min}$ ) or hypotension (systolic blood pressure $<90 \mathrm{mmHg}$ ). DEX treatment was discontinued when AWS symptoms in patients were not relieved in 3 days.

\section{Lorazepam treatment}

Lorazepam is among the most commonly used benzodiazepine drugs. Patients in this group started to receive $2 \mathrm{mg}$ intravenous lorazepam every 8 hours and the dose was increased to $2 \mathrm{mg}$ intravenous lorazepam every 60 minutes if symptoms of AWS continued to progress. Once sedated, lorazepam dosing was maintained at $2 \mathrm{mg}$ intravenously every 6 hours. Oxygen saturation monitoring was necessary during treatment as escalating doses of lorazepam may pose a risk to respiratory distress. Lorazepam treatment was discontinued when AWS symptoms in patients were not relieved in 3 days.

\section{Statistical analysis}

The categorical data are expressed as counts (or percentages) and were analyzed by chi-square tests; the quantitative data (continuous variables) are presented as means \pm standard deviations (SDs) and were analyzed by $t$-tests. The $\mathrm{P}$ value of less than 0.05 was considered statistically significant. The statistical analysis for the differences between groups was performed on GraphPad Software version 8.0.

\section{Results}

\section{Patients demographic and disease characteristics}

This study was conducted in a cohort of 59 patients with mean age of 65.8 years (range, 53-80 years). Among them, 58 of 59 patients were male and all patients presented with middle or advanced stages (T2-T4) of head and neck cancer. The majority of patients' tumor stage was T3 (32/59, $54.2 \%)$, followed by T4 $(16 / 59,27.1 \%)$ and T2 (11/59, $18.6 \%)$. The most common primary tumor site in this study 
was in tongue $(33 / 59,55.9 \%)$, followed by buccal $(13 / 59$, $22.0 \%)$, floor of mouth $(6 / 59,10.2 \%)$, gingiva $(4 / 59,6.8 \%)$, others $(3 / 59,5.1 \%$, Table 1$)$.

\section{Patient complications and outcome}

Common complications after surgical reconstruction were found in both groups, such as hematoma, flap crisis and flap necrosis. Besides, some rare complications occurred, such as cardiac arrest and Wernicke's encephalopathy (WE), in which classic symptoms are mental status changes, ocular dysfunction and a gait apraxia. And only one patients accepted propofol due to no effect of two drugs. Tracheotomy is a routine management for those patients with high risk for dyspnea. Owing to limiting of sample size, we combined the tracheotomy with complications for the convenience of statistical analysis.

In DEX group, for the time to recover, after the AWS, most people relieved within 3 days (26/33), some patients relieved till 5 days (2/33) and others needed more than 7 days (5/33). Among complications, 5 cases were hematoma, flap crisis and flap necrosis. Each one case was cardiac arrest and WE. Besides, 2 cases were tracheotomy. The incidence of complications and tracheotomy was $27.3 \%$ (9/33). Mean time of recovering was 3.2 \pm 2.2 days. For those patients with complications, the mean time of recovering was $5.1 \pm 2.8$ days.

In lorazepam group, for the time to recover, after the AWS, most people relieved within 3 days (21/26), some patients relieved till 5 days $(2 / 26)$ and others needed more than 7 days (3/26). The incidence of complications and tracheotomy was $15.4 \%$ (4/26). Mean time of recovering was $3.2 \pm 2.1$ days. Two cases were tracheotomy and each one case was for hematoma and poor efficacy. For those patients with complications, the mean time of recovering was $4.0 \pm 3.5$ days. Statistical analysis outcomes were shown in Table 1.

\section{Discussion}

AWS is a common complication of anesthesia after surgery in elderly patients (19). AWS increased the risk of flap crisis and caused longer duration of mechanical ventilation in patients, thus leading to a longer stay and severe complications in the ICU $(20,21)$. More and more researches are revealing that alcohol consumption increased the risk of developing cancers in head and neck and others $(22,23)$. What's more, due to the high incidence of alcohol abuse in head and neck cancer patients, it might take longer to recover from AWS. Both DEX and lorazepam are firstline drugs to treat the AWS, and it's necessary to assess the efficacy of the two drugs.

For the incidence of postoperative complications, we found no significant difference between DEX and lorazepam $(\mathrm{P}=0.27)$. In DEX group, 5 cases had hematoma, flap crisis and flap necrosis, which associated with insufficient restriction of activities. The typical symptoms of AWS were hyperactivity and delirium tremens with symptoms including agitation, hallucinations, disorientation, tachycardia, hypertension, fever, agitation, and diaphoresis (24), which may have potential relationship with this complications. And 2 cases were tracheotomy, which was needed for keeping the airway open and maintaining respiratory function. Besides, rare complications occurred in 2 cases, namely cardiac arrest and WE. For the cardiac arrest patient, we immediately took emergency treatments, such as cardiopulmonary resuscitation (CPR), and then the patients recovered heartbeat. The WE patient recovered by suppling vitamin B1 and balancing electrolyte. DEX can exhibit bradycardia and hypotension $(25,26)$, so we consider hemodynamic changes associates with these complications (not including tracheotomy) $(27,28)$. Besides, Alcoholism is the most common etiologic factor associated with WE and it can happen in patients with a nutritional deficiency state (29), which is common in patients undergoing major surgery. Due to only 1 case for each, we cannot confirm the hypothesis in statistics. In lorazepam group, total 4 cases of complications and tracheotomy after surgical reconstruction occurred. Among them, 2 cases were hematoma and 1 was tracheotomy. One case showed no any relieving symptom after accepting lorazepam and DEX, so we used the propofol, an anesthetic drug, to control and relieve the AWS, while the patient had longer time to recover.

To further compare the efficacy difference of the two drugs, we analyzed the outcome of treatment. For the time of recovering of AWS, In DEX group, the mean time was $3.2 \pm 2.2$ days; and it was $3.2 \pm 2.1$ days in lorazepam group. No significant difference was found $(\mathrm{P}=0.87)$. For those patients with complications, the mean time of recovering, in DEX group, the mean time was $5.1 \pm 2.8$ days; and it was $4.0 \pm 3.5$ days in lorazepam group. This comparison also showed no significant difference $(\mathrm{P}=0.55)$.

Among various reported medicines to treat patients with AWS (30-32), lorazepam is considered as the first-line strategies (33). However, lorazepam can cause sedation, which is a primary concern with multiple drug regimens when it 
is excessive (34), especially for the patients who underwent surgical reconstruction of head and neck with pharyngeal cavity lessened. Lorazepam can also cause respiratory suppression, resulting in endotracheal intubation. Even at ostensibly therapeutic doses, lorazepam treatment can lead to cognitive and psychomotor impairment in patients (35). For high doses or continuous infusion of lorazepam, metabolic acidosis can occur because of the accumulation of propylene glycol and some patients also developed apatheia in their follow-ups (36-38). In addition, lorazepam administration after anesthesia can lead to acute respiratory arrest, which may be due to increased sensitivity of the $\gamma$-aminobutyric acid (GABA) neurotransmitter receptors (39). The combination of lorazepam and antipsychotics, such as haloperidol (Haldol) and olanzapine (Zyprexa), can reduce agitation and hallucinations in delirium patients (40). However, due to their side effects including decreasing the seizure threshold, hyperthermia, hypotension, prolonged QTc and neuroleptic malignant syndrome, antipsychotics is never be considered as first-line therapy or monotherapy for AWS and should be used with caution (41-43). DEX has also been often used for clinical AWS management (43). DEX does not have the neurotransmitter activity and it usually is used as an adjunct therapy for AWS (16). Compared with lorazepam, DEX does not cause respiratory suppression, but can control hyperadrenergic symptoms associated with AWS, thus decreases autonomic hyperactivity and minimize over-sedation (44-46). Patients treated with DEX exhibited bradycardia and hypotension, which can be relieved by temporary discontinuation of DEX and monitoring closely (47). In a published severe case, the patient treated with DEX in normal dose developed a sudden cardiac arrest and was immediately administered external chest compression (48). Overall, DEX rarely causes complications, even in the case of long-term or short-term high-dose use (49-51). Our research has some limitations. First of all, retrospective study can only partially explain our goal. Secondly, we had few indicators to evaluate the efficacy. Then, we did not carry out followup work, unable to understand whether the patient had complications after discharge.

\section{Conclusions}

AWS are common symptoms in patients with alcohol dependence after operation. Scholars have put forward many suggestions to prevent and control it. However, no obvious effective drug was found. DEX and lorazepam are main stream drugs. Our retrospective study found there is no significant difference in recovering time of
AWS, complications occurring and its recovering time, after randomly accepting DEX or lorazepam. In our department, we take methods to prevent and control AWS, such as preoperative education, humanistic care, support of the family, deinstitutionalization, and creating a quiet, soothing, warm environment can alleviate agitation and hallucinations. We cautiously use drugs to alleviate AWS.

\section{Acknowledgments}

We would like to thank professor Joseph I. Helman (Case Western Reserve University) for his help in polishing our paper.

Funding: The work was supported by the National Natural Science Foundation of China (grant number 81771127).

\section{Footnote}

Reporting Checklist: The authors have completed the STROBE reporting checklist. Available at https://fomm. amegroups.com/article/view/10.21037/fomm-21-76/rc

Data Sharing Statement: Available at https://fomm. amegroups.com/article/view/10.21037/fomm-21-76/dss

Conflicts of Interest: All authors have completed the ICMJE uniform disclosure form (available at https://fomm. amegroups.com/article/view/10.21037/fomm-21-76/coif). The authors have no conflicts of interest to declare.

Ethical Statement: The authors are accountable for all aspects of the work in ensuring that questions related to the accuracy or integrity of any part of the work are appropriately investigated and resolved. The study was conducted in accordance with the Declaration of Helsinki (as revised in 2013) and individual consent for this retrospective analysis was waived. When this study started six years ago, retrospective research usually did not require ethics. This study only collected patient clinical data, did not interfere with the treatment plan of the patient, and would not bring risks to the patient's outcome. The researcher will do his best to protect the information provided by the patient from leaking personal privacy.

Open Access Statement: This is an Open Access article distributed in accordance with the Creative Commons Attribution-NonCommercial-NoDerivs 4.0 International 
License (CC BY-NC-ND 4.0), which permits the noncommercial replication and distribution of the article with the strict proviso that no changes or edits are made and the original work is properly cited (including links to both the formal publication through the relevant DOI and the license). See: https://creativecommons.org/licenses/by-nc-nd/4.0/.

\section{References}

1. Manthey J, Shield KD, Rylett M, et al. Global alcohol exposure between 1990 and 2017 and forecasts until 2030: a modelling study. Lancet 2019;393:2493-502.

2. Jiang H, Room R, Hao W. Alcohol and related health issues in China: action needed. Lancet Glob Health 2015;3:e190-1.

3. Liu Y, Chen H, Sun Z, et al. Molecular mechanisms of ethanol-associated oro-esophageal squamous cell carcinoma. Cancer Lett 2015;361:164-73.

4. Thun MJ, Peto R, Lopez AD, et al. Alcohol consumption and mortality among middle-aged and elderly U.S. adults. N Engl J Med 1997;337:1705-14.

5. Marcantonio ER. Delirium in Hospitalized Older Adults. N Engl J Med 2017;377:1456-66.

6. McKinley MG. Alcohol withdrawal syndrome overlooked and mismanaged? Crit Care Nurse 2005;25:40-2, 44-8; quiz 49.

7. Neyman KM, Gourin CG, Terris DJ. Alcohol withdrawal prophylaxis in patients undergoing surgical treatment of head and neck squamous cell carcinoma. Laryngoscope 2005;115:786-90.

8. Ungur LA, Neuner B, John S, et al. Prevention and therapy of alcohol withdrawal on intensive care units: systematic review of controlled trials. Alcohol Clin Exp Res 2013;37:675-86.

9. Kim HY, Lee JE, Kim HY, et al. Volatile sedation in the intensive care unit: A systematic review and meta-analysis. Medicine (Baltimore) 2017;96:e8976.

10. Keating GM. Dexmedetomidine: A Review of Its Use for Sedation in the Intensive Care Setting. Drugs 2015;75:1119-30.

11. Linn DD, Loeser KC. Dexmedetomidine for Alcohol Withdrawal Syndrome. Ann Pharmacother 2015;49:1336-42.

12. Amato L, Minozzi S, Davoli M. Efficacy and safety of pharmacological interventions for the treatment of the Alcohol Withdrawal Syndrome. Cochrane Database Syst Rev 2011;(6):CD008537.

13. Pandharipande PP, Pun BT, Herr DL, et al. Effect of sedation with dexmedetomidine vs lorazepam on acute brain dysfunction in mechanically ventilated patients: the MENDS randomized controlled trial. JAMA 2007;298:2644-53.

14. Kress JP, Pohlman AS, O'Connor MF, et al. Daily interruption of sedative infusions in critically ill patients undergoing mechanical ventilation. $\mathrm{N}$ Engl J Med 2000;342:1471-7.

15. Newman JP, Terris DJ, Moore M. Trends in the management of alcohol withdrawal syndrome. Laryngoscope 1995;105:1-7.

16. DeMuro JP, Botros DG, Wirkowski E, et al. Use of dexmedetomidine for the treatment of alcohol withdrawal syndrome in critically ill patients: a retrospective case series. J Anesth 2012;26:601-5.

17. Martinotti G, di Nicola M, Frustaci A, et al. Pregabalin, tiapride and lorazepam in alcohol withdrawal syndrome: a multi-centre, randomized, single-blind comparison trial. Addiction 2010;105:288-99.

18. Sullivan JT, Sykora K, Schneiderman J, et al. Assessment of alcohol withdrawal: the revised clinical institute withdrawal assessment for alcohol scale (CIWA-Ar). Br J Addict 1989;84:1353-7.

19. Monte R, Rabuñal R, Casariego E, et al. Analysis of the factors determining survival of alcoholic withdrawal syndrome patients in a general hospital. Alcohol Alcohol 2010;45:151-8.

20. Rayner SG, Weinert CR, Peng H, et al. Dexmedetomidine as adjunct treatment for severe alcohol withdrawal in the ICU. Ann Intensive Care 2012;2:12.

21. Reddy V, Adegbala O, Ando T, et al. Comparison of InHospital Outcomes of Patients With-Versus-Without Atrial Fibrillation and Alcohol Withdrawal Syndrome. Am J Cardiol 2019;124:1056-8.

22. Attar E, Dey S, Hablas A, et al. Head and neck cancer in a developing country: a population-based perspective across 8 years. Oral Oncol 2010;46:591-6.

23. Boffetta P, Hashibe M. Alcohol and cancer. Lancet Oncol 2006;7:149-56.

24. Awissi DK, Lebrun G, Coursin DB, et al. Alcohol withdrawal and delirium tremens in the critically ill: a systematic review and commentary. Intensive Care Med 2013;39:16-30.

25. Xu A, Wan L. Dexmedetomidine-induced polyuric syndrome and hypotension. J Clin Anesth 2018;44:8-9.

26. Martin-Flores M, Mostowy MM, Pittman E, et al. Investigation of associations between preoperative acepromazine or dexmedetomidine administration and 
development of arterial hypotension or bradycardia in dogs undergoing ovariohysterectomy. J Am Vet Med Assoc 2019;255:193-9.

27. Yong J, Hibbert P, Runciman WB, et al. Bradycardia as an early warning sign for cardiac arrest during routine laparoscopic surgery. Int J Qual Health Care 2015;27:473-8.

28. Maeda H, Kuriyama A, Tanaka T. Prolonged hypotension associated with Wernicke's encephalopathy. Eur J Clin Nutr 2018;72:168-9.

29. Sinha S, Kataria A, Kolla BP, et al. Wernicke Encephalopathy-Clinical Pearls. Mayo Clin Proc 2019;94:1065-72.

30. Wright T, Myrick H, Henderson S, et al. Risk factors for delirium tremens: a retrospective chart review. Am J Addict 2006;15:213-9.

31. Barrons R, Roberts N. The role of carbamazepine and oxcarbazepine in alcohol withdrawal syndrome. J Clin Pharm Ther 2010;35:153-67.

32. Spies CD, Otter HE, Hüske B, et al. Alcohol withdrawal severity is decreased by symptom-orientated adjusted bolus therapy in the ICU. Intensive Care Med 2003;29:2230-8.

33. Ghiasi N, Marwaha R. Lorazepam. StatPearls. Treasure Island (FL): StatPearls Publishing StatPearls Publishing LLC., 2019.

34. Hecksel KA, Bostwick JM, Jaeger TM, et al. Inappropriate use of symptom-triggered therapy for alcohol withdrawal in the general hospital. Mayo Clin Proc 2008;83:274-9.

35. Lader M. Benzodiazepine harm: how can it be reduced? $\mathrm{Br}$ J Clin Pharmacol 2014;77:295-301.

36. Arroliga AC, Shehab N, McCarthy K, et al. Relationship of continuous infusion lorazepam to serum propylene glycol concentration in critically ill adults. Crit Care Med 2004;32:1709-14.

37. Nelsen JL, Haas CE, Habtemariam B, et al. A prospective evaluation of propylene glycol clearance and accumulation during continuous-infusion lorazepam in critically ill patients. J Intensive Care Med 2008;23:184-94.

38. Horinek EL, Kiser TH, Fish DN, et al. Propylene glycol accumulation in critically ill patients receiving continuous intravenous lorazepam infusions. Ann Pharmacother 2009;43:1964-71.

39. Huitink J, Buitelaar D. Management of drug and alcohol withdrawal. N Engl J Med 2003;349:405-7; author reply 405-7.
40. MacLaren R, Krisl JC, Cochrane RE, et al. A case-based approach to the practical application of dexmedetomidine in critically ill adults. Pharmacotherapy 2013;33:165-86.

41. O'Brien JM Jr, Lu B, Ali NA, et al. Alcohol dependence is independently associated with sepsis, septic shock, and hospital mortality among adult intensive care unit patients. Crit Care Med 2007;35:345-50.

42. Darrouj J, Puri N, Prince E, et al. Dexmedetomidine infusion as adjunctive therapy to benzodiazepines for acute alcohol withdrawal. Ann Pharmacother 2008;42:1703-5.

43. Baddigam K, Russo P, Russo J, et al. Dexmedetomidine in the treatment of withdrawal syndromes in cardiothoracic surgery patients. J Intensive Care Med 2005;20:118-23.

44. Muzyk AJ, Fowler JA, Norwood DK, et al. Role of $\alpha 2-$ agonists in the treatment of acute alcohol withdrawal. Ann Pharmacother 2011;45:649-57.

45. Hodges B, Mazur JE. Intravenous ethanol for the treatment of alcohol withdrawal syndrome in critically ill patients. Pharmacotherapy 2004;24:1578-85.

46. Trudell JR, Messing RO, Mayfield J, et al. Alcohol dependence: molecular and behavioral evidence. Trends Pharmacol Sci 2014;35:317-23.

47. Franck J, Jayaram-Lindström N. Pharmacotherapy for alcohol dependence: status of current treatments. Curr Opin Neurobiol 2013;23:692-9.

48. Zahr NM, Kaufman KL, Harper CG. Clinical and pathological features of alcohol-related brain damage. Nat Rev Neurol 2011;7:284-94.

49. Shehabi Y, Ruettimann U, Adamson H, et al. Dexmedetomidine infusion for more than 24 hours in critically ill patients: sedative and cardiovascular effects. Intensive Care Med 2004;30:2188-96.

50. Grof TM, Bledsoe KA. Evaluating the use of dexmedetomidine in neurocritical care patients. Neurocrit Care 2010;12:356-61.

51. Tang JF, Chen PL, Tang EJ, et al. Dexmedetomidine controls agitation and facilitates reliable, serial neurological examinations in a non-intubated patient with traumatic brain injury. Neurocrit Care 2011;15:175-81.

doi: 10.21037/fomm-21-76

Cite this article as: Liu Y, Xu Y, Li Q, Zhang L. Alcohol withdrawal management in patients undergoing head and neck reconstruction-a retrospective analysis. Front Oral Maxillofac Med 2021;3:36. 